\title{
REGIME AUTORITÁRIO DITATORIAL BRASILEIRO DA DÉCADA DE 1960 E VIOLAÇÕES DE DIREITO HUMANOS RECONHECIDAS NO CASO GOMES LUND E OUTROS DESAPARECIDOS NA GUERRILHA DO ARAGUAIA
}

\author{
${ }^{1}$ Eudes Vitor Bezerra \\ ${ }^{2}$ Marcelo Negri Soares
}

\section{RESUMO}

O ensaio iniciou-se na premissa de que a Corte Interamericana de Direitos Humanos tem exercido importante papel no cenário da América Latina. Prova disso é sentença produzida no caso Gome Lund e outros que repercutiu na reparabilidade dos direitos de desaparecidos e familiares. Com o tema de fundo trilhou as perspectivas doutrinárias em consonância com julgado em comento da Corte Interamericana, tendo como base o novo constitucionalismo. Utilizaremos o método hipotético-dedutivo, com aporte na pesquisa dogmática e jurisprudencial, tendo como hipótese inicial, por meio de um estudo apurado a eficácia dos Direitos Humanos e a (in)aplicabilidade da Lei $\mathrm{n}^{\circ}$ 9.140/95.

Palavras-chave: Proteção dos Direitos Humanos, Sistema Interamericano, Constitucionalismo Transformador, Jurisprudência da Corte Interamericana, Sistema Jurídico, Gome Lund e Outros

\section{RÉGIMEN DICTADURA AUTORITARIA DÉCADA DE BRASIL DE 1960 Y VIOLACIÓNES DERECHOS HUMANOS RECONOCIDOS EN GOMES LUND CASO Y OTRAS QUE FALTA EN LA GUERRILLA ARAGUAIA}

\begin{abstract}
RESUMEN
La premisa de que la Corte Interamericana de Derechos Humanos ha desempeñado un papel importante en la escena latinoamericana. En caso de condena "Gome Lund y otros" que resonaron en la reparabilidad de las personas desaparecidas. Vamos a utilizar el método hipotético-deductivo, con inversiones en la investigación dogmática y jurisprudencial, con la hipótesis inicial a través de un estudio evaluó la efectividad de los Derechos Humanos y la (in)aplicabilidad de la Ley 9.140/95 .
\end{abstract}

Palabras-claves: Protección de los Derechos Humanos, El sistema Interamericano, El Constitucionalismo Transformador, La Jurisprudencia del Tribunal de Justicia, Sistema Legal, Gome Lund y Otros

\footnotetext{
1 Doutorando pela Pontifícia Universidade Católica de São Paulo, PUC, São Paulo (Brasil). Coordenação do Curso de Direito pela Universidade Nove de Julho - UNINOVE, São Paulo (Brasil). E-mail: eudesvitor@adv.oabsp.org.br

2 Doutor pela Pontifícia Universidade Católica de São Paulo, PUC, São Paulo (Brasil). Professor pela Universidade Federal do Rio de Janeiro - UFRJ, Rio de Janeiro (Brasil). E-mail: negri@negrisoares.com.br
} 


\section{INTRODUÇÃO}

Que os direitos humanos não são frutos, somente, de um determinado acontecimento, eis que trata-se de um processo temporal e complexo no qual os direitos humanos vão se formando, já sabemos, todavia, alguns eventos violam esses direitos e suas marcas ficam ad eternum, como, e.g., o caso "Gomes Lund e outros" da Guerrilha do Araguaia.

Destarte, analisaremos as violações e suas consequências, em especial as violações mencionadas na primeira geração ${ }^{1}$ de direitos humanos (para alguns dimensões para outros blocos de direitos), bem como as de segunda e terceira.

Não obstante, múltiplos foram os mecanismos criados para proteger os direitos dos homens, entretanto, no presente ensaio, o que debruçamos com maior afinco fora a Corte Interamericana de Direitos Humanos - $\mathrm{CIDH}$, eis que trabalharemos nos capítulos abaixo alguns casos brasileiros processados perante a Corte Interamericana.

Assim, através do método hipotético-dedutivo e com aporte na pesquisa dogmática e, principalmente, jurisprudencial, uma vez que a presente pesquisa tem como escopo analisar julgados da Corte Interamericana.

Desta forma, no primeiro capítulo traremos a baila o surgimento de um novo constitucionalismo no sistema interamericano, demonstrando uma ruptura por intermédio dos movimentos sociais.

No segundo capítulo será abordado o papel da Corte Interamericana de Direitos Humanos, bem como os critérios utilizados para a concessão de medidas provisórias de urgência e critérios para as decisões.

Em ato contínuo, analisaremos no terceiro capítulo 5 (cinco) casos levados à Corte Interamericana envolvendo o Brasil.

No quarto capítulo será realizada a análise do caso "Gomes Lund e outros" da Guerrilha do Araguaia, os fatos que ensejaram a sentença, a sentença em si, bem como as medidas ordenadas pela Corte Interamericana e seu cumprimento.

\footnotetext{
${ }^{1}$ Nossa doutrina, especializada, prefere a expressão "dimensão", porquanto o a expressão “geração" pressupõe um momento que sucede ao outro, e, em se tratando de direitos humanos, não ocorre o fenômeno da sucessão, mais sim um sobreposição de fenômenos, tal como ocorre com as dimensões.
} 
Já no último capítulo, em breves palavras, falaremos, sobre a Lei ${ }^{\circ} 9.140$ de 4 de dezembro de 1995, em que o Brasil reconheceu sua responsabilidade pela morte de opositores políticos.

Por fim, são realizadas as conclusões na qual verificaremos as principais violações de direito humanos no caso "Gomes Lund e outros" da Guerrilha do Araguaia.

\section{O NOVO CONSTITUCIONALISMO LATINO-AMERICANO}

É cediço que a partir do final da década de 1970 se viu o declínio dos regimes ditatoriais, que era avesso aos direitos humanos, com grande impulso na própria Convenção Americana de Direitos Humanos, alcançando efetividade na passagem para os regimes democráticos, gradativamente, na década seguinte, abrangendo a Argentina, o Brasil, o Chile e o Uruguai.

O surgimento de um novo constitucionalismo no sistema interamericano, por meio dos movimentos sociais e melhor aparelhamento da Justiça, acabou por se legitimar como importante instrumento para a garantia legislativa dos direitos humanos no contexto regional.

Consequentemente, têm-se o fortalecimento das instituições democráticas com a atuação do Ministério Público, Defensoria e demais entidades encarregadas do combate às violações de direitos humanos e proteção aos grupos mais vulneráveis.

Vale ressaltar que na década seguinte, mais precisamente no ano de 1988, foi promulgada no Brasil sua atual Constituição, denominada por alguns de Constituição Cidadã.

Mais tarde, o MERCOSUL veio a reforçar a integração regional. Atualmente, a Corte Interamericana de Direito Humanos tem papel decisivo na repressão de violação a direitos humanos.

\section{O PAPEL DA CORTE INTERAMERICANA DE DIREITOS HUMANOS - CIDH}

Nos mais de 35 anos de existência da Corte Interamericana de Direitos Humanos CIDH (denominada neste escrito, por vezes, simplesmente Corte), a realidade tem sido uma mudança de paradigma político-social entre os povos das Américas. Isso se deve muito à consciência de que o trabalho não se encerra em uma decisão ou na emissão de um parecer, mas na "materialização real através do diálogo dinâmico com instituições nacionais, particu- 
larmente com os órgãos jurisdicionais",2

Portanto, a força da decisão da Corte vem da cooptação das lideranças nacionais dos países destinatários para garantir imediato cumprimento dessas decisões, com base na aplicação do princípio da cooperação, sem prejuízo do concomitante acompanhamento da Corte até a solução esperada.

Esse é o diferencial dessa Corte que só faz por melhorar os direitos humanos no âmbito de sua jurisdição, mantendo a independência nacional (decorrente da soberania), mas que por adesão, proclama a prevalência dos direitos humanos propondo solução pacífica dos conflitos pelo diálogo.

\subsection{CLASSIFICAÇÃO DE MEDIDAS PROVISÓRIAS DE URGÊNCIA PROFERIDAS PELA CORTE INTERAMERICANA}

Diante do permissivo contido no art. 63.2 da Convenção Americana sobre Direitos Humanos e 27 do Regulamento do Tribunal, a Corte Interamericana divulgou a sistematização dos assuntos envolvidos nas resoluções sobre Direitos Humanos, em medidas provisórias de urgência com vista ao reconhecimento definitivo de direito legalmente garantidos, em 3 (três) principais categorias ou critérios para as decisões, a saber:

\subsubsection{PRIMEIRO CRITÉRIO DE CLASSIFICAÇÃO: QUANTO ÀS PESSOAS PROTEGIDAS (DITOS BENEFICIÁRIOS) POR MEDIDAS PROVISÓRIAS DE URGÊNCIA OU EM DIREITO PROTEGIDO POR DECISÃO DEFINITIVA DA CORTE}

Nessa categoria estão às decisões que versão sobre beneficiários protegidos. Assim, leva-se em conta as características, condições ou qualidades de pessoas a serem protegidas pela medida ou decisão, tendo em vista sua relação com os direitos humanos a serem garantidos ou assegurados.

Este critério que leva em conta os beneficiários protegidos admite subdivisão classificatória, nos seguintes subtipos:

\footnotetext{
2 "Ao longo deste caminho, a Corte decidiu mais de 200 casos, emitiu quase 300 sentenças, mais de 20 pareceres consultivos, e ofereceu proteção imediata a pessoas e grupos de pessoas através de sua função cautelar. (...) De acordo com essa dinâmica, são os próprios operadores nacionais quem, através do diálogo jurisprudencial e de um adequado controle de convencionalidade, sempre no âmbito de suas competências, conferem valor real às decisões da Corte Interamericana." (PORTO, Humberto Antonio Sierra. Apresentação. In: Boletim de Jurisprudência - Corte Interamericana de Direitos Humanos. N. 1, agosto - outubro de 2014, p. 2. Disponível em: http://www.corteidh.or.cr/sitios/libros/todos/docs/boletin1por.pdf / Acesso em: 06/01/2016).
} 
a) supostas vítimas, vítimas, parentes destas, representantes das supostas vítimas, especialmente as vítimas que figurem em casos sub-judice perante a Corte Interamericana;

b) inquiridos em processos perante a Corte Interamericana;

c) defensores dos direitos humanos;

d) pessoas encarceradas, privadas de liberdade ou detidas em centros de detenção;

e) pessoas condenadas à pena de morte;

f) operadores da Justiça no país destinatário da medida ou decisão;

g) pessoas envolvidas com a garantia do exercício da liberdade de expressão;

h) grupos de pessoas ou membros de comunidades;

i) mulheres (direito de vulneráveis e hipossuficientes);

j) meninas e meninos (direito de vulneráveis e hipossuficientes).

Esta subclassificação, assim como as demais a seguir, estão completas, de acordo com as decisões e outros atos proferidos pela Corte até o primeiro semestre de 2015. Não obstante, o trabalho de classificação é sempre uma obra aberta, que admite novas inclusões, ao passo que não pretendemos exaurir o tema.

\subsubsection{SEGUNDO CRITÉRIO DE CLASSIFICAÇÃO: QUANTO AO MODO DE PROCESSAMENTO DO REQUERIMENTO PARA QUE A CORTE ADOTE MEDIDAS PROVISÓRIAS}

Esta classificação destina-se a cobrir qualquer fase processual (seja antes do ajuizamento do processo na Corte, seja na fase inicial, estando já em curso processo ou em processo findo, com decisão definitiva já prolatada) sempre quando haja medidas intermediárias aprovadas e pendente de cumprimento ou com perspectivas de ser aprovada pela Corte Interamericana. A competência varia entre a Comissão Interamericana (órgão da Corte que realiza triagem e parecer prévio antes do ajuizamento) ou da própria Corte interamericana (que tem competência quando o processo já está instaurado, podendo delegar o monitoramento do cumprimento da decisão para agentes internos do país destinatário).

Assim, essa classificação recebe a subdivisão em:

a) interpelação pela Comissão sobre as questões não apresentadas à Corte;

b) medidas que dizem respeito a casos submetidos à Corte antes de emitir o seu acórdão (espécie de tutela antecipada ou medida de urgência);

c) medidas arquivadas, mantidas ou aplicadas após a prolação do acórdão / sentença.

Estes três subtipos cobrem o modo de processamento de requerimento para adoção pela Corte de medidas provisórias em momentos processuais distintos, seja prévio, no 
curso ou após findo o processo com a decisão definitiva.

\subsubsection{TERCEIRO CRITÉRIO DE CLASSIFICAÇÃO: QUANTO À REAFIRMAÇÃO OU NÃO DA VIGÊNCIA E EFICÁCIA DAS MEDIDAS PROVISÓRIAS PROFERIDAS PELA CORTE (EFETIVAÇÃO OU LEVANTAMENTO DE DECISÕES PROVISÓRIAS)}

Esta categoria tem como objetivo identificar tanto os requerimentos denegados (rejeitados ou recusados) em medidas provisórias que dizem respeito à sua validade ou modo de efetivação em fase de execução (podendo implicar em levantamento total ou parcial e/ou seguir seu cumprimento) e os requerimentos de ampliação de medidas recentemente adotadas.

Ao decidir sobre as medidas interlocutórias (provisórias) ou avaliar a eficácia das medidas adotadas, o Tribunal de Justiça deve observar o disposto no artigo 63.2 da Convenção Americana, que exige três condições concorrentes a serem observadas para que se possa manter medidas provisórias até seu efetivo cumprimento: a) casos de extrema gravidade; b) casos de urgência, e; c) quando se fizer necessária a medida para evitar danos irreparáveis.

Então, essa categoria admite a seguinte subdivisão, em específico, vejamos:

a) providências para medidas provisórias denegadas;

b) levantamento total de medidas provisórias;

c) levantamento parcial de medidas provisórias;

d) recusa de requerimento de levantamento parcial de medidas provisórias;

e) recusa de requerimento de levantamento completo de medidas ou decisões da Corte;

f) ampliação de medidas provisórias;

g) denegação do requerimento de ampliação de medidas provisórias;

h) suspensão e cessação dos efeitos de medidas provisórias;

i) adoção de novas medidas provisórias em face de um levantamento total ou parcial das medidas já adotadas e que se revelaram ineficazes sob o ponto de vista dos objetivos da decisão; j) desistência ou retirada do requerimento de medidas provisórias.

Em todos esses casos se vê a preocupação com a vigência e eficácia da medida provisória

\section{BRASIL: NOTÍCIA DAS DECISÕES E OUTROS ATOS PROFERIDOS PELA CORTE INTER AMERICANA}

O Brasil teve 5 (cinco) casos contenciosos resolvidos pela Corte. Logicamente que os casos submetidos à Corte Interamericana, que envolvem ou envolveram o Brasil, não se resumem a estes, pois, como já explicitado, a Corte se pronuncia em pareceres, consultas, me- 
didas provisórias, dentre outros, não somente na decisão definitiva dos casos contenciosos.

Assim, utilizar-se-á o sistema de classificação acima exposto para listar todos os casos ocorridos na Corte Interamericana, com envolvimento do Brasil, como segue:

\subsection{LISTAGEM DOS CASOS LEVADOS À CORTE INTERAMERICANA ENVOLVENDO O BRASIL}

Abaixo relatamos os casos brasileiros processados perante a Corte Interamericana, seguindo alguns critérios:

Nesse primeiro critério, quanto às pessoas protegidas, o Brasil teve 5 (cinco) casos, sendo todos os envolvendo presos (pessoas encarceradas, privadas de liberdade ou detidas em centros de detenção), mas 02 (dois) destes casos, especificamente, referem-se às crianças e adolescentes. Confira no quadro abaixo:

\begin{tabular}{|c|c|c|}
\hline \multicolumn{3}{|c|}{$\begin{array}{l}\text { PRIMEIRO CRITÉRIO DE SISTEMATIZAÇÃO } \\
\text { (quanto às pessoas protegidas) }\end{array}$} \\
\hline $\begin{array}{l}\text { Critério de classi- } \\
\text { ficação }\end{array}$ & Caso ou assunto e resoluções & $\begin{array}{l}\text { Direitos } \\
\text { protegidos }\end{array}$ \\
\hline \multirow{4}{*}{$\begin{array}{l}\text { Pessoas encarcera- } \\
\text { das, privadas de } \\
\text { liberdade ou detidas } \\
\text { em centros de de- } \\
\text { tenção }\end{array}$} & $\begin{array}{l}\text { 1. Penitenciária Urso Branco - Brasil (Res. Corte: } 18 \\
\text { junho de } 2002,29 \text { de agosto de 2002, } 22 \text { de abril de } \\
2004,07 \text { de julho de } 2004,21 \text { de setembro de } 2005 \text {, } \\
02 \text { de maio de } 2008 \text { e } 25 \text { de novembro de } 2009 \text { ) }\end{array}$ & \multirow{5}{*}{$\begin{array}{l}\text { A vida e a } \\
\text { integridade } \\
\text { físico-pessoal }\end{array}$} \\
\hline & $\begin{array}{l}\text { 2. Penitenciária "Dr. Sebastião Martins Silveira ", em } \\
\text { Araraquara, São Paulo - Brasil (Res. Corte: } 30 \text { de } \\
\text { setembro de 2006) }\end{array}$ & \\
\hline & $\begin{array}{l}\text { 3. Complexo Penitenciário de Curado, Recife - Per- } \\
\text { nambuco. (Res. da Corte: } 22 \text { de maio de } 2014 \text { ) }\end{array}$ & \\
\hline & $\begin{array}{l}\text { 4. Complexo Penitenciário de Pedrinhas, no Estado } \\
\text { do Maranhão. (Res. da Corte: medidas cautelares em } \\
16 \text { dezembro de } 2013 \text { e ampliação com medidas } \\
\text { provisórias em } 14 \text { de novembro de } 2014 \text { ) }\end{array}$ & \\
\hline $\begin{array}{l}\text { Crianças } \\
\text { (obrigação estatal de }\end{array}$ & $\begin{array}{l}\text { 5. Unidade de Internação Socioeducativa (Res. Cor- } \\
\text { te: } 25 \text { fevereiro de } 2011,26 \text { de abril de } 2012,21 \text { de } \\
\text { agosto de } 2013 \text { e } 29 \text { de janeiro, 2014) }\end{array}$ & \\
\hline
\end{tabular}


adotar medidas protetivas especiais)
6. Crianças e adolescentes privados de liberdade no

"Complexo do Tatuapé de" da FEBEM - São Paulo Brasil (Res. Corte: 17 novembro 2005, 30 de novembro de 2005 e 03 de julho de 2007)

Em todos os casos acima listados, existem resoluções as que tratam também do segundo critério de sistematização, quanto ao modo de processamento do requerimento para que a Corte adote medidas provisórias, na subclassificação das medidas requeridas pela Comissão Interamericana ante os assuntos não submetidos (ou seja, omitidos) à Corte IDH. Deixamos de listar novamente, para não ocasionar duplicidade de informação. Assim, nesse segundo critério, basta relacionar o seguinte caso:

\begin{tabular}{|c|c|c|}
\hline \multicolumn{3}{|c|}{$\begin{array}{l}\text { SEGUNDO CRITÉRIO DE SISTEMATIZAÇÃO } \\
\text { (quanto ao modo de processamento de medidas provisórias na Corte) }\end{array}$} \\
\hline $\begin{array}{l}\text { Critério de classi- } \\
\text { ficação }\end{array}$ & Caso ou assunto e resoluções & $\begin{array}{l}\text { Direitos prote- } \\
\text { gidos }\end{array}$ \\
\hline $\begin{array}{l}\text { Medidas requeridas } \\
\text { em casos submeti- } \\
\text { dos à apreciação da } \\
\text { Corte antes da } \\
\text { emissão de sua de- } \\
\text { cisão definitiva }\end{array}$ & $\begin{array}{l}\text { 7. Caso Gomes Lund e outros (Guerrilha do Ara- } \\
\text { guaia) vs. Brasil (Res. Corte: } 15 \text { de junho de } 2009 \text { e } \\
\text { resolução de supervisão em } 17 \text { de outubro de } \\
2014 \text { )** }\end{array}$ & $\begin{array}{l}\text { Responsabilidade } \\
\text { por desapareci- } \\
\text { dos políticos }\end{array}$ \\
\hline
\end{tabular}

As resoluções citadas atendem também o terceiro critério, quanto à efetivação ou levantamento de decisões provisórias, mas que deixamos de representar novamente no quadro a seguir, tendo em vista que representaria duplicidade.

No terceiro critério, são os mesmos casos já relacionados no primeiro critério, mas que destacamos as diferentes datas das resoluções, para separar as datas das resoluções já qualificadas acima. São elas, conforme tabela abaixo:

\section{TERCEIRO CRITÉRIO DE SISTEMATIZAÇÃO (efetivação ou levantamento de decisões provisórias)} \begin{tabular}{|l|l|l}
\hline Critério de classi- & Caso ou assunto e resoluções
\end{tabular} Direitos 


\begin{tabular}{|c|c|c|}
\hline & $\begin{array}{l}\text { 8. Crianças e adolescentes privados de liberdade no } \\
\text { "Complexo do Tatuapé de" da FEBEM - São Paulo - } \\
\text { Brasil (Res. Corte: } 25 \text { de novembro de } 2008 \text { ) }\end{array}$ & \\
\hline \multirow[t]{2}{*}{$\begin{array}{l}\text { Levantamento total } \\
\text { de medidas provisó- } \\
\text { rias }\end{array}$} & $\begin{array}{l}\text { 9. Penitenciária Urso Branco - Brasil (Res. Corte: } 25 \\
\text { de agosto de 2011) }\end{array}$ & \\
\hline & $\begin{array}{l}\text { 10. Penitenciária "Dr. Sebastião Martins Silveira ", em } \\
\text { Araraquara, São Paulo - Brasil (Res. Corte: } 25 \text { de } \\
\text { novembro, 2008) }\end{array}$ & $\begin{array}{l}\text { A vida e a } \\
\text { integridade } \\
\text { físico-pessoal }\end{array}$ \\
\hline $\begin{array}{l}\text { Recusa do requeri- } \\
\text { mento de levanta- } \\
\text { mento total ou com- } \\
\text { pleto das medidas }\end{array}$ & $\begin{array}{l}\text { 11. Unidade de Internação Socioeducativa (Res. } \\
\text { Corte: } 01 \text { de setembro de } 2011 \text { e } 20 \text { de novembro de } \\
\text { 2012) }\end{array}$ & \\
\hline $\begin{array}{l}\text { Indeferimento do } \\
\text { pedido de ampliação } \\
\text { de medidas provisó- } \\
\text { rias }\end{array}$ & $\begin{array}{l}\text { 12. Crianças e adolescentes privados de liberdade no } \\
\text { "Complexo do Tatuapé de" da FEBEM - São Paulo - } \\
\text { Brasil (Res. Corte: } 4 \text { de julho de } 2006 \text { ) }\end{array}$ & \\
\hline
\end{tabular}

Em conclusão, verificamos que todas as resoluções atinentes ao Brasil se referem, de certa forma, ao direito à vida e/ou integridade física, apenas um caso refere-se à responsabilidade por desaparecidos políticos.

\section{CASO GOMES LUND E OUTROS ("GUERRILHA DO ARAGUAIA") VS. BRASIL (SUP ERVISÃO DE CUMPRIMENTO DE SENTENÇA)}

Caso Gomes Lund e outros envolvidos na Guerrilha do Araguaia foi sentenciado em 24 de novembro de 2010, sendo que a Corte expediu em 17 de outubro de 2014 uma resolução para supervisão do cumprimento de sentença. Esta última que nos interessa neste tópico derradeiro.

Recordemos os fatos que ensejaram a sentença.

A ditadura militar foi implantada no Brasil, através de golpe militar, há mais de 50 anos (em 1964), que depôs o governo João Goulart. O regime militar se apoiou nas normas de segurança nacional e normas de exceção, como os atos institucionais, que acobertavam sob o 
manto legal os atos de desmandos repressivos, do Estado até culminar na promulgação do Ato Institucional $\mathrm{n}^{\mathrm{o}} 5$, de dezembro de 1968. Houve o fechamento do Congresso Nacional, a censura da imprensa, a suspensão dos direitos individuais e políticos, limitação da liberdade de expressão e da liberdade de reunião, não cabendo o habeas corpus perante o Poder Judiciário, introduzindo-se, também, a pena perpétua e a pena de morte na aplicação da "Justiça".

Naturalmente que tais medidas eram impopulares, manifestando-se contrários diversos setores da sociedade, que começaram a ser organizar ainda na década de 1960.

Assim, a guerrilha manifestou-se como movimento de luta armada ocorrido na região do Araguaia, situada na divisa de Tocantins e Pará. Iniciou-se em 1972, no mandato do Presidente Médici (1969-1974), confrontos armados entre os guerrilheiros e as forças armadas brasileiras (especialmente tropas do exército), com inspiração em revoluções socialistas, a exemplo das ocorridas em Cuba e na China. Os guerrilheiros (inicialmente 70 integrantes) não aguentavam mais o governo militar, que promovia o desaparecimento de presos políticos, com parcela de mortes simulando atropelamentos, suicídios inventados e tentativas frustradas de fuga.

Mais de 50 mil pessoas foram detidas ainda nos seis primeiros meses da ditadura; desses foram mais de 20 mil submetidos a tortura; 354 desaparecidos e mortos políticos; 130 foram obrigados a se exilar em outros países; 4.862 tiveram mandatos e direitos políticos suspensos, mais de 500 camponeses assassinados.

As forças armadas reagiram às investidas da Guerrilha do Araguaia em três frentes: Operação Papagaio, Operação Sucuri e Operação Marajoara, movimentando mais de cinco mil militares. O resultado foi a vitória dos militares, que acabaram com o movimento guerrilheiro em 1975. A batalha foi sangrenta, contabilizando 98 (noventa e oito) mortos, sendo 59 militantes do PcdoB, 19 agricultores guerrilheiros e 20 militares. $^{3}$

O relatório da decisão em comento dá conta, vejamos:

\footnotetext{
${ }^{3}$ Estes números são estimados, conforme estudos específicos. (Maciel, Lício Augusto. Guerrilha do Araguaia: Relato de um combatente. Itu: Schoba Ebook, 2013). “A Guerrilha do Araguaia foi o maior acontecimento militar da resistência armada ao golpe de 1964. Começou antes mesmo do Al-5, quando dezenas de homens, mulheres e dirigentes partidários, vindos dos grandes centros do sul, sudeste e nordeste, principalmente, criaram uma força de combate que se estabeleceu na região genericamente chamada de Araguaia, por causa do grande rio que domina aquela geografia. Com adesão de camponeses locais, desenvolveram-se trabalho político e, depois, ação militar, enfrentando numerosas forças do Exército, enviadas para lá a fim de exterminar a resistência. Implantado no norte do país, esse movimento revolucionário foi pouco conhecido no seu tempo, obscurecido pela censura e pelo isolamento. Só agora, mais de 40 anos depois, ganha a dimensão política que lhe corresponde." (AMORIM, Carlos. Araguaia - histórias de amor e de guerra. São Paulo: Record, 2014.)
} 
"Denominou-se ao movimento de resistência ao regime militar integrado por alguns membros do novo Partido Comunista do Brasil. No início de 1972, às vésperas da primeira expedição do Exército à região do Araguaia, a Guerrilha contava com cerca de 70 pessoas, em sua maioria jovens. Entre abril de 1972 e janeiro de 1975, um contingente de entre três mil e dez mil integrantes do Exército, da Marinha, da Força Aérea e das Polícias Federal e Militar empreendeu repetidas campanhas de informação e repressão contra os membros da Guerrilha do Araguaia. Nas primeiras campanhas, os guerrilheiros detidos não foram privados da vida, nem desapareceram. Os integrantes do Exército receberam ordem de deter os prisioneiros e de "sepultar os mortos inimigos na selva, depois de sua identificação"; para isso, eram "fotografados e identificados por oficiais de informação e depois enterrados em lugares diferentes na selva". No entanto, após uma "ampla e profunda operação de inteligência, planejada como preparativo da terceira e última investida de contra insurgência", houve uma mudança de estratégia das forças armadas. Em 1973, a "Presidência da República, encabeçada pelo general Médici, assumiu diretamente o controle sobre as operações repressivas e a ordem oficial passou a ser de eliminação" dos capturados."

A resistência conseguiu sofisticar mais o sistema, pois a partir de 1974, oficialmente não mais se falava em mortes nas prisões ou assassinato de opositores, o governo não mais assumia essas ocorrências, pois os presos políticos mortos passaram a simplesmente serem tidos como desaparecidos. O governo encobria qualquer informação mediante a imposição do silêncio à imprensa e divulgando esclarecimento à população de que não existia o tal movimento. Ao final daquele mesmo não, já não haviam guerrilheiros no Araguaia.

Por que o Brasil, que entrou no curso democrático a partir de 1984, não instaurou imediatamente processo para punição penal dos responsáveis pelas violações de direitos humanos do período da ditadura militar? Justamente porque deram uma face de legalidade, quando o Estado editou a Lei de Anistia de 1979. Assim, somente com a lei no 9.140/95, veio o reconhecimento da responsabilidade do Estado por tais mortes e desaparecimentos. O Estado brasileiro é confesso, mas tardiamente. Após décadas, muitos responsáveis já nem mais estão vivos.

\subsection{SENTENÇA}

Recordados os fatos que levaram à sentença, o processo se iniciou em 26 de março de 2009, quando a Comissão Interamericana de Direitos Humanos submeteu à Corte uma demanda em face da República Federativa do Brasil (União), em nome de pessoas desaparecidas 
no contexto da Guerrilha do Araguaia e seus familiares, após longo estudo iniciado nos idos de 1995, a conclusão foi pela responsabilidade do Estado demandado por violações dos direitos humanos estabelecidos em detrimento das vítimas desaparecidas e de familiares dos desaparecidos, informando ser indevida a aplicação da Lei de Anistia e em virtude da ineficácia das ações judiciais não penais interpostas no marco do presente caso. ${ }^{4}$

Em verdade, a demanda visou apurar a responsabilidade do Estado pela detenção arbitrária, tortura e desaparecimento de 70 pessoas (do Partido Comunista do Brasil e camponeses), em operações militares para debelar a Guerrilha do Araguaia, utilizando as forças do Exército brasileiro entre 1972 e 1975, sob o comando da ditadura militar do Brasil (19641985).

Segundo o que se apurou, o Estado não iniciou a investigação penal para julgar e punir as pessoas responsáveis pelos desaparecimentos, tendo em vista o que ditava a Lei $\mathrm{n}^{\circ} 6.683 / 79$. Assim, o acesso a informação sobre a Guerrilha do Araguaia aos familiares de desaparecidos e executado.

A Comissão solicitou ao Tribunal que declare que o Estado brasileiro responsável pela violação dos direitos humanos envolvidos e que ordene a adoção de medidas de reparação. ${ }^{5}$

A Sentença, dentre outros, estabeleceu as reparações em 24 de novembro de 2010. Declarou a República Federativa do Brasil responsável pelo desaparecimento provocado de 62 pessoas integrantes da Guerrilha do Araguaia e ainda determinou medidas de reparação. Ainda, declarou que a forma de interpretação e aplicação pelo Estado brasileiro da Lei $n^{\circ}$. 6.683, aprovada em 1979 (denominada Lei de Anistia), vedou a possibilidade de investigação e punição das violações já assinaladas em direitos humanos. Todavia, até 2014 ainda haviam medidas ordenadas pela Corte sem o devido cumprimento.

\footnotetext{
${ }^{4}$ Tratam se violações aos artigos I, XXV e XXVI da Declaração Americana, bem como dos artigos 4, 5 e 7, em conexão com o artigo 1.1 da Convenção Americana, em detrimento das vítimas desaparecidas; nos artigos XVII da Declaração Americana e 3, em relação com o artigo 1.1 da Convenção Americana; nos artigos I da Declaração Americana e 5, em conexão com o artigo 1.1 da Convenção Americana; no artigo 13, em conexão com o artigo 2 da Convenção Americana; nos artigos XVIII da Declaração Americana e 8.1 e 25 da Convenção Americana, em relação com os artigos 1.1 e 2 da mesma Convenção, nos artigos XVIII da Declaração Americana e 8.1 e 25, em relação com o artigo 1.1 da Convenção Americana.

${ }^{5}$ A comissão apurou infringência aos artigos 3 (direito ao reconhecimento da personalidade jurídica), 4 (direito à vida), 5 (direito à integridade pessoal), 7 (direito à liberdade pessoal), 8 (garantias judiciais), 13 (liberdade de pensamento e expressão) e 25 (proteção judicial), da Convenção Americana sobre Direitos Humanos, em conexão com as obrigações previstas nos artigos 1.1 (obrigação geral de respeito e garantia dos direitos humanos) e 2 (dever de adotar disposições de direito interno) da Convenção Americana sobre Direitos Humanos.
} 


\subsubsection{Medidas ordenadas pela Corte e seu cumprimento}

A sentença, dentre outros, contempla as principais medidas ordenadas pela Corte, de responsabilidade do Brasil, conforme sistematizado no quadro abaixo, a saber:

\begin{tabular}{|c|c|c|}
\hline \multicolumn{3}{|c|}{ MEDIDAS ORDENADAS PELA CORTE NA SENTENÇA } \\
\hline Medida & Detalhamento do assunto & \\
\hline $\begin{array}{l}\text { Responsabilidade } \\
\text { penal }\end{array}$ & $\begin{array}{l}\text { Em prazo razoável o Estado deve corrigir o curso das } \\
\text { apurações, passando a conduzir de maneira eficaz a } \\
\text { investigação, determinação, julgamento e eventual } \\
\text { punição dos responsáveis, aplicando sanções em função } \\
\text { da violação dos direitos às garantias judiciais e à pro- } \\
\text { teção judicial, em detrimento dos familiares das pessoas } \\
\text { envolvidas em desaparecimento e execução - conforme } \\
\text { arts. } 8.1 \text { e } 25.1 \text { da Convenção Americana. }\end{array}$ & $\mathrm{X}$ \\
\hline $\begin{array}{l}\text { Injunção legal e } \\
\text { jurisprudencial }\end{array}$ & $\begin{array}{l}\text { Adequar o direito interno em razão da interpretação e } \\
\text { aplicação que o Brasil deu à Lei de Anistia, o que ou- } \\
\text { trora serviu a impedir a investigação, persecução, cap- } \\
\text { tura, julgamento e eventual punição dos responsáveis } \\
\text { por violações contínuas e permanentes como os desa- } \\
\text { parecimentos forçados - conforme art. } 2 \text { da Convenção } \\
\text { Americana. }\end{array}$ & $\mathrm{X}$ \\
\hline $\begin{array}{l}\text { Julgamento de } \\
\text { militares }\end{array}$ & $\begin{array}{l}\text { Acusados ou supostos responsáveis que sejam ou que } \\
\text { foram funcionários militares, sejam examinadas perante } \\
\text { a jurisdição ordinária, e não no foro militar. }\end{array}$ & $\mathrm{X}$ \\
\hline $\begin{array}{l}\text { Acesso à Justiça, } \\
\text { acesso à infor- } \\
\text { mação e publici- }\end{array}$ & $\begin{array}{l}\text { O Estado deve assegurar o pleno acesso e capacidade de } \\
\text { ação dos familiares das vítimas em todas as etapas da } \\
\text { investigação e do julgamento dos responsáveis, sendo } \\
\text { que os resultados dos processos deverão ser publica- }\end{array}$ & $\mathrm{X}$ \\
\hline
\end{tabular}




\begin{tabular}{|c|c|c|c|}
\hline dade das decisões & $\begin{array}{l}\text { mente divulgados, para que a sociedade brasileira co- } \\
\text { nheça os fatos, bem como seus responsáveis. }\end{array}$ & & \\
\hline $\begin{array}{l}\text { Paradeiro das } \\
\text { vítimas e entrega } \\
\text { dos restos mor- } \\
\text { tais }\end{array}$ & $\begin{array}{l}\text { O Estado deve realizar esforços possíveis, com brevi- } \\
\text { dade, para determinar o paradeiro das vítimas da Guer- } \\
\text { rilha do Araguaia, destacando recursos humanos e téc- } \\
\text { nicos adequados. Ainda, uma vez previamente identi- } \\
\text { ficados, os restos mortais das vítimas desaparecidas } \\
\text { deverão ser entregues a seus familiares, tão logo seja } \\
\text { possível e sem custo para eles, para que possam sepul- } \\
\text { tá-los de acordo com suas crenças. }\end{array}$ & & $\mathrm{X}$ \\
\hline $\begin{array}{l}\text { Tratamento psi- } \\
\text { cológico, psiqui- } \\
\text { átrico ou médico }\end{array}$ & $\begin{array}{l}\text { Oferecer atendimento médico e psicológico ou psiqui- } \\
\text { átrico, de forma gratuita e imediata, adequada e efetiva, } \\
\text { por meio das instituições públicas especializadas de } \\
\text { saúde, às vítimas que assim o solicitem no prazo de seis } \\
\text { meses, contados a partir da notificação da Sentença. No } \\
\text { caso da senhora Elena Gibertini Castiglia, por residir na } \\
\text { Itália, o Estado deverá conceder-lhe o montante de US\$ } \\
7.500,00 \text {, para que possa receber o tratamento na loca- } \\
\text { lidade de sua residência. }\end{array}$ & $\mathrm{X}$ & \\
\hline Publicidade & $\begin{array}{l}\text { Publicação da Sentença: em seis meses da notificação, o } \\
\text { Estado deve publicar a Sentença nos seguintes veículos: } \\
\text { no Diário Oficial, sem as notas de rodapé; em um jornal } \\
\text { de ampla circulação nacional, apenas o resumo oficial; } \\
\text { no sítio eletrônico do Estado, a íntegra, com disponibi- } \\
\text { lidade mínima de um ano; sem sítio eletrônico ade- } \\
\text { quado, como livro eletrônico. Ainda, em um ano da } \\
\text { notificação da Sentença, o Estado deve promover ato de } \\
\text { reconhecimento de responsabilidade internacional so- } \\
\text { bre os fatos e violações declaradas na decisão, em uma } \\
\text { cerimônia pública na presença de autoridades nacionais } \\
\text { e das vítimas, com ampla divulgação nos meios de } \\
\text { comunicação. }\end{array}$ & $\mathrm{X}$ & \\
\hline
\end{tabular}




\begin{tabular}{|c|c|c|c|}
\hline $\begin{array}{l}\text { Capacitação das } \\
\text { Forças Armadas } \\
\text { sobre direitos } \\
\text { humanos }\end{array}$ & $\begin{array}{l}\text { O Estado deve dar continuidade às ações já desenvol- } \\
\text { vidas na capacitação de integrantes das Forças Armadas } \\
\text { sobre os princípios e normas de proteção dos direitos } \\
\text { humanos e sobre os limites a que devem estar subme- } \\
\text { tidos. Deve, ainda, implementar, em um prazo razoável, } \\
\text { um programa ou curso permanente e obrigatório sobre } \\
\text { direitos humanos, destinado a todos os níveis hierár- } \\
\text { quicos das Forças Armadas. O programa deve incluir o } \\
\text { estudo da Sentença proferida neste caso, a jurisprudên- } \\
\text { cia da Corte sobre graves violações de direitos huma- } \\
\text { nos, jurisdição penal militar e obrigações do Brasil em } \\
\text { direitos humanos derivadas dos tratados internacionais. }\end{array}$ & $X$ & \\
\hline $\begin{array}{l}\text { Tipificação do } \\
\text { delito de desapa- } \\
\text { recimento força- } \\
\text { do }\end{array}$ & $\begin{array}{l}\text { O Estado deve adotar, em um prazo razoável, medidas } \\
\text { para tipificar o delito de desaparecimento forçado de } \\
\text { pessoas, com prosseguimento legislativo, incluindo a } \\
\text { ratificação da Convenção Interamericana sobre o De- } \\
\text { saparecimento Forçado de Pessoas. }\end{array}$ & & $x^{6}$ \\
\hline $\begin{array}{l}\text { Julgamento e } \\
\text { punição }\end{array}$ & $\begin{array}{l}\text { O Estado deverá adotar todas as ações para garantir } \\
\text { efetivo julgamento, e se o caso, a punição em relação ao } \\
\text { desaparecimento forçado, utilizando mecanismos exis- } \\
\text { tentes no direito interno. }\end{array}$ & & $X$ \\
\hline $\begin{array}{l}\text { Informação sobre } \\
\text { a Guerrilha do }\end{array}$ & $\begin{array}{l}\text { O Estado deve continuar desenvolvendo as iniciativas } \\
\text { de busca, sistematização e publicação, garantindo o } \\
\text { acesso a toda informação sobre a Guerrilha do Ara- }\end{array}$ & $X$ & \\
\hline
\end{tabular}

\footnotetext{
${ }^{\overline{6}}$ Esse item, embora ainda não implementado, está em tramitação no Poder Legislativo. Assim, o Projeto de Lei do Senado n. 245/2011 define desaparecimento forçado de pessoa como sendo qualquer ação de apreender, deter, sequestrar, arrebatar, manter em cárcere privado, impedir a livre circulação ou de qualquer outro modo privar alguém de sua liberdade, em nome de organização política, ou de grupo armado ou paramilitar, do Estado, suas instituições e agentes ou com a autorização, apoio ou aquiescência de qualquer destes, ocultando ou negando a privação de liberdade ou deixando de prestar informação sobre a condição, sorte ou paradeiro da pessoa a quem deva ser informado ou tenha o direito de sabê-lo. $O$ desaparecimento forçado de pessoas também passará a ser incluído no rol dos crimes hediondos (Lei 8.072/1990). (Fonte: Site do Senado, Redação. Plenário aprova tipificação do crime de desaparecimento forçado de pessoa - 27/08/2013. Disponível em http://www12.senado.leg.br/noticias/materias/2013/08/27/plenario-aprova-tipificacao-do-crime-de-desapar ecimento-forcado-de-pessoa, acesso em: 10/01/2016).
} 


\begin{tabular}{|l|l|l|l|}
\hline $\begin{array}{l}\text { Araguaia e do } \\
\text { regime militar }\end{array}$ & $\begin{array}{l}\text { guaia, bem como da informação relativa a violações de } \\
\text { direitos humanos ocorridas durante o regime militar. }\end{array}$ & O Estado deve pagar indenização por dano material e \\
imaterial e promover a restituição de custas e gastos, \\
nas quantias determinadas nos parágrafos 304, 311 e \\
318 da Sentença. Os beneficiários da indenização são os \\
Indenização e \\
restituição pecu- \\
niária
\end{tabular}


recursos e atribuições que lhe possibilitem o cumpri- $\mathrm{X}^{7}$ mento eficaz de seus objetivos.

Este quadro revela problemas ainda sem solução, pendência que merecem atenção do Governo do Brasil.

\section{Lei n 9.140/95 e Comissão Especial sobre Mortos e Desaparecidos Políticos}

Foi somente com a Lei $\mathrm{n}^{\circ} 9.140$ de 4 de dezembro de 1995, que o Brasil reconheceu sua responsabilidade pela morte de opositores políticos, reconhecendo sua participação direta nos assassinatos ocorridos de 2 de setembro de 1961 a 15 de agosto de 1979 no contexto da Guerrilha do Araguaia.

A lei menciona 136 desaparecidos, em conclusão dos estudos desenvolvidos por familiares e militantes de direitos humanos; criando também a Comissão Especial sobre Mortos e Desaparecidos Políticos para buscar o reconhecimento de outros desaparecidos, mediante solicitação de familiares.

A Lei $n^{\circ}$ 9.140/95 também determinou a possibilidade da concessão de uma reparação pecuniária aos familiares dos mortos e desaparecidos políticos, concedida no âmbito da Comissão Especial que, até 2010, já tinham sido pagos o equivalente a US\$ 3.772.000,00 (três milhões, setecentos e setenta e dois mil dólares dos Estados Unidos da América), a familiares de 58 desaparecidos da Guerrilha do Araguaia.

\footnotetext{
7 “A Comissão Nacional da Verdade, posterioridade à emissão da Sentença, foi criada e colocada em funcionamento através da Lei $n^{\circ}$.

12.528/2011, de 18 de novembro de 2011, e instituída em 16 de maio de 2012, com o fim de "examinar e esclarecer as graves violações de direitos humanos praticadas (entre 18 de setembro 1946 e 5 de outubro de 1988), a fim de efetivar o direito à memória e à verdade histórica e promover a reconciliação nacional", e com os objetivos de "esclarecer os fatos e circunstâncias dos casos de graves violações de direitos humanos; promover o esclarecimento circunsranciado dos casos de torturas, mortes, desaparecimentos forçados, ocultação de cadáveres e sua autoria; e recomendar a adoção de medidas e políticas públicas para prevenir violação de direitos humanos, assegurar a sua não repetição e promover a efetiva reconciliação nacional". 133. O Tribunal constata que o Estado acolheu e cumpriu a referida recomendação, uma vez que considera que, tal como foi afirmado no parágrafo 297 da Sentença, o estabelecimento de uma Comissão Nacional da Verdade "é um mecanismo importante, entre outros aspectos, para cumprir a obrigação do Estado de garantir o direito de conhecer a verdade sobre o ocorrido", e porque "pode contribuir para a construção e preservação da memória histórica, o esclarecimento de fatos e a determinação de responsabilidades institucionais, sociais e políticas". 134. Além disso, a Corte toma nota da manifestação do Estado na audiência privada no sentido de que, para a referida Comissão Nacional da Verdade, a coleta e provisão de informação sobre as operações militares realizadas no período da Guerrilha do Araguaia, são prioritárias através da criação de um grupo de trabalho específico, cujo objetivo é investigar o evento conhecido como Guerrilha do Araguaia, concentrando-se nas operações militares e nos mortos e desaparecidos na região. A esse respeito, o Tribunal ressalta que o trabalho e futuras conclusões da referida Comissão poderiam ter impacto nas medidas de reparação ordenadas nos pontos dispositivos nono, décimo e décimo sexto da Sentença, relacionados à investigação penal dos fatos e violações do presente caso, à localização e identificação do paradeiro das vítimas e à sistematização e publicação de informação relacionada à Guerrilha do Araguaia." (Trecho da Resolução Supervisão da Corte expedida em 17 de outubro de 2014 no caso Gomes Lund e outros (Guerrilha do Araguaia) vs. Brasil).
} 


\section{Conclusão}

O caso Gomes Lund fora propiciado pelo regime autoritário ditatorial brasileiro da década de 1960 e acarretou diversas violações aos direitos humanos, como e.g., os direitos de segunda geração - direitos de liberdade - que em decorrência do advento da terceira geração de direitos humanos cujo princípio fundante foi a fraternidade e, consequentemente, da Declaração dos Direitos Humanos que é norma cogente se tornou exigível a todos os seres humanos.

A Constituição brasileira de 1988 e o fenômeno da constitucionalização do direito que prima pela (re)leitura da Carta sob o prisma da dignidade da pessoa humana, bem como os tratados dos quais o Brasil é signatário exigem o respeito ao piso mínimo de direitos estabelecidas que foram internacionalizados pelo neoconstitucionalismo.

A despeito disso, tratando-se de jus cogens, ou seja, norma exigível contra todos a despeito de ser ou não signatário dos tratados ao Estado incumbe assegurar a todos que estiverem em seu território o exercício regular destes direitos. Isso porque, a soberania estatal é relativizada no que concerne aos direitos humanos.

Diante do caráter relativo da soberania no que tange aos direitos humanos e da Declaração dos Direitos e Deveres do Homem foi instituída a pela Organização dos Estados Americanos a Comissão Interamericana de Direitos Humanos a quem oferecer recomendações, medidas provisórias de emergência, analisar e julgar casos visando resguardar tais direitos.

Analisou-se neste trabalho o movimento de constitucionalização do direito e o papel da Corte Interamericana de Direitos Humanos nos casos brasileiros submetidos à sua apreciação, especialmente o caso "Gomes Lund e outros" da Guerrilha do Araguaia que apurou a responsabilidade do Estado brasileiro pela prisão arbitrária, tortura e desparecimento de 70 pessoas, bem como a inércia deste em apurar penalmente os responsáveis.

A sentença da Corte considerou a República Federativa do Brasil responsável pelos desaparecimentos e, inclusive, ordenou medidas de reparação e prevenção contra novas barbáries, dentre elas: punição criminal aos militares, indenização pecuniária, informação às famílias das vítimas a respeito da data de seu falecimento, capacitação dos militares a respeito de direitos humanos, instituir a Comissão Nacional da Verdade entre outas, conforme abordado anteriormente.

Dessa forma, constatou-se a importância da Corte Interamericana dos Direitos Humanos em face dos Estados violadores de tais direitos, permitindo que, de fato, exista um piso mínimo de igualdade entre todos os seres humanos dos países Americanos. 


\section{Bibliografia}

AMAZONAS, João, ANTERO, Luiz Carlos e SILVA, Eumano. Uma epopeia pela liberdade: Guerrilha do Araguaia 30 anos. São Paulo: Ed. Anita Garibaldi, 2002.

AMORIM, Carlos. Araguaia - histórias de amor e de guerra. São Paulo: Record, 2014

ARENDT, Hannah. A condição humana. Trad.: Roberto Raposo. Rio de Janeiro: Forense

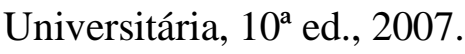

ARENDT, Hannah. Origens do Totalitarismo. São Paulo: Companhia das Letras, 1990.

ARISTÓTELES. Metafísica - Livro IV. Tradução de Marcelo Perine. São Paulo: Edições Loyola, 2002. BACHELARD, Gaston. O Direito de Sonhar. Rio de Janeiro: Bertrand Brasil, 1994.

AUGUSTO, Agnaldo Del Nero. A Grande Mentira. 1a ed., Rio de Janeiro: Ed. Biblioteca do Exército, 2001.

BEBIANO, Rui. O poder da imaginação - juventude, rebeldia e resistência nos anos 60 . Coimbra: Angelus Novus, 203.

BERTOLINO, Osvaldo. Maurício Grabois: uma vida de combates. São Paulo: Anita Garibaldi: Instituto Maurício Grabois, 2004.

BERTOLINO, Osvaldo; e Outros. Guerrilha do Araguaia. São Paulo: Editora Anita Garibaldi, 1996. BRUM, Liniane Haag. Antes do Passado. Rio de Janeiro: Arquipélago Editorial, 2012.

BLOCH, Ernest. O Princípio Esperança - Vol. 1. Trad. Nélio Schneider. Rio de Janeiro: Ed. UERJ; Contraponto, 2005.

BLOCH, Ernest. The Spirit of Utopia. Stanford, Califórnia, USA: Stanford University Press, 2000.

BLOOM, Harold. Shakespeare: a invenção do humano. Trad. José O’Oshea. Objetiva, 1995. 
BOBBIO, Norberto. Esquerda e Direita. São Paulo: Ed. Unesp, 1995.

BORDIEU, Pierre. O poder simbólico. 2a ed., Rio de Janeiro: Bertrand Brasil, 1998.

CAMPOS FILHO, Romualdo Pessoa. Guerrilha do Araguaia - Esquerda em Armas. Goiânia: Universidade Federal de Goiás, 1997.

CANTINHO, Maria João. "Walter Benjamin e a história Messiânica. Contra a visão histórica do progresso". Revista Philosophica, n. 37, Departamento de Filosofia da Faculdade de Letras de Lisboa, Lisboa, Ed. Clibri, 2011.

CARDINA, Miguel. A esquerda radical. Coimbra, Portugal: Angelus Novus, 2010.

CARDOSO, Ciro Flamarion. Testemunha Ocular - História e Imagem. Baurú: Edusc, 2004.

CARNEIRO, Ana: e CIOCCARI, Marta. Retrato da Repressão Política no Campo: Brasil 1962-1985 - Camponeses Torturados, Mortos e Desaparecidos; Direito à Memória e à Verdade. Brasília: Ministério do Desenvolvimento Agrário, Dezembro 2011.

CARVALHO, Luiz Maklouf. O Coronel Rompe o Silêncio, Lício Augusto Ribeiro, que matou e levou tiros na caçada aos guerrilheiros do Araguaia, conta sua história. Rio de Janeiro: Objetiva, 2004.

CARVALHO, Luiz Maklouf. Mulheres que foram à luta armada. São Paulo: Globo, 1998.

CATROGA, Fernando. Os passos do homem como restolho do tempo: memória e fim do fim da história. Coimbra, Almedina, 2009.

CAVALCANTI, Klester. O Nome da Morte. São Paulo: Planeta do Brasil, 2006.

CLUTTERBUCK, Richard. Guerrilheiros e Terroristas. Rio de Janeiro: Biblioteca do Exército, 1980. 
CUÉLLAR, Alejandro Castillejo. Los archivos del dolor - Ensayos sobre la violencia y el recuerdo en la sudáfrica contemporánea. Bogotá: Universidad de los Andes, Centro de Estudos Socioculturales - CESO, Ediciones Uniandes, 2009.

FÉLIX, Loiva Otero e GOETTEMS, Miriam Barcellos (org.). Cultura Grega Clássica. Porto Alegre: Editora UFRS, 1989.

FOUCAULT, Michel. A ordem do discurso. 6a ed., São Paulo: Ed. Loyola, 1996.

FOUCAULT, Michel. Microfísica do Poder. 5a ed., São Paulo: Graal, 1985.

MIR, Luís. A Revolução Impossível - A esquerda e a luta armada no Brasil. São Paulo: Best Seller; Círculo do Livro, 1994.

MORAIS, Taís e SILVA, Eumano. Operação Araguaia - Arquivos Secretos da Guerrilha. São Paulo: Geração Editorial, 2005.

MOURA E SOUSA, Aluísio Madruga de. Movimento Comunista Brasileiro; Guerrilha do Araguaia - Revanchismo: A Grande Verdade. Brasília: Edição Pessoal, 2002.

MOURA, Clóvis. Diário da Guerrilha do Araguaia. São Paulo: Alfa-Ômega, 1985.

NAPOLITANO, Marco. O Regime Militar Brasileiro- 1964-1985. São Paulo: Atual. 1998.

POMAR, Wladimir. Araguaia: O Partido e a Guerrilha - Documentos Inéditos. São Paulo: Ed. Brasil Debates, Col. Brasil Estudos, nº 2, 1980.

PORTELA, Fernando. Guerra de Guerrilhas no Brasil. 2a ed., São Paulo: Global,1987. REPÚBLICA, Presidência da. Direito à Memória e à Verdade. Brasília: Comissão Especial sobre Mortos e Desaparecidos Políticos do Ministério da Justiça e Secretaria Especial dos Direitos Humanos, 2007.

RICHOPO, Neide. A esquerda no Brasil: um estudo de caso. Tese de Mestrado apresentada ao Departamento de Ciência Política da Universidade de São Paulo, USP. São Paulo: 1988. 
RICOEUR, Paul. A memória, a história e o esquecimento. Campinas: Unicamp, 2010, $2^{\mathrm{a}}$ reimpressão.

SANTOS, Boaventura de Sousa. "Para além do pensamento abissal: das linhas globais a uma ecologia de saberes". In: SANTOS, Boaventura de Sousa e MENESES, Maria Paula (Orgs.). Epistemologias do Sul. Coimbra: Almedina, CES, 2009. SÃO PAULO, Mitra Arquidiocesana de. Brasil: Nunca Mais. Tomos I a VI. Petrópolis: Vozes, 1985-1988. SIRKYS, Alfredo. Os Carbonários. $14^{a}$ ed., São Paulo: Record, 1998.

SOUSA, Eudoro. Dionísio em Creta e outros ensaios. Introdução. António Telmo. Lisboa: Imprensa Nacional e Casa da Moeda, 2004.

STUDART, Hugo A Lei da Selva: Estratégias, Imaginário e Discurso dos Militares sobre a Guerrilha do Araguaia. São Paulo: Geração, 2006.

TRINDADE, Antônio Augusto Cançado. A proteção dos Direitos Humanos nos 454 plano nacional e internacional: perspectivas brasileiras. Brasília: F. Naumann, 1992.

TRINDADE, Antônio Augusto Cançado. Bases para un Proyecto de Protocolo a la Convención Americana sobre Derechos Humanos: para fortalecer su mecanismo de protección. San José de Costa Rica: Corte Interamericana de Derechos Humanos, 2003. 